\title{
Aqueous-Phase, Palladium-Catalyzed Suzuki Reactions under Mild Conditions
}

\author{
Yueqin Cai ${ }^{1}$, Gonghua Song ${ }^{2 *}$, Zhongyuan $\mathrm{Wu}^{1}$, Jiawei Zhang ${ }^{1}$ \\ ${ }^{1}$ School of Chemistry and Molecular Engineering, East China University of Science and Technology, Shanghai, China \\ ${ }^{2}$ Shanghai Key Laboratory of Chemical Biology, Institute of Pesticides \& Pharmaceuticals, \\ East China University of Science and Technology, Shanghai, China \\ Email: caiyueqin@ecust.edu.cn, *Ghsong@ecust.edu.cn
}

Received July 2, 2013; revised August 2, 2013; accepted August 9, 2013

Copyright (C) 2013 Yueqin Cai et al. This is an open access article distributed under the Creative Commons Attribution License, which permits unrestricted use, distribution, and reproduction in any medium, provided the original work is properly cited.

\begin{abstract}
Water-soluble ionic liquid-supported diols have been used as phosphine-free ligands in Suzuki couplings of aryl idides/bromides/chlorides under mild conditions in aqueous solvent. It was found that 2,2-bis((1-hexylimidazolium)mehyl) propane-1,3-diol hexafluorophosphate (4) in combination with palladium (II) salts gave the most significant catalyst. Suzuki couplings of aryl iodides/bromides occurred efficiently at room temperature in water/acetonitrile. Notably, the reactions of hydrophilic aryl bromides gave high yields in neat water. The catalyst $\mathrm{PdCl}_{2}-\mathbf{4}$ was recycled five times in Suzuki couplings in water before catalyst activity began to significantly drop. The average yield of five cycles was $>95 \%$ per cycle.
\end{abstract}

Keywords: Suzuki Reaction; Ionic Liquid-Supported Diols; Phosphine-Free Ligands

\section{Introduction}

Palladium-catalyzed Suzuki cross-coupling reaction, widely used synthetic methodology, is one of the most powerful methods for the formation of $\mathrm{C}-\mathrm{C}$ and $\mathrm{C}$-heteroatom bonds [1-3]. Generally, triphenylphosphines are the most commonly used ligands to achieve reasonable levels of activity [4]. However, phosphine ligands like triarylphosphines typically show high toxicant toward the environment, and are difficult to be separated from organic products. Recently, it has been reported that ionic liquids (ILs) have been used as media in the cross-coupling reaction to serve as the mobile supports of Pd catalysts due to environmental, economic, and safety concerns $[5,6]$. Although ionic liquids have been developed as phosphine-free ligands, most of these ligands are based on ordinary ionic liquids without functionalized groups, therefore coordinating abilities of these phosphine-free catalytic systems are often very poor [7,8]. It means that catalytic activity using these ionic liquids as ligands is lower compared with phosphine-containing ligands. Thus, the development of more effective methodologies for improving the ligation ability of ionic liquids has a longstanding interest in organic synthesis. A feasible method

\footnotetext{
*Corresponding author.
}

to achieve such improvement could be the introduction of functionalized groups into ILs. For this purpose, the ionic liquids with electron-donating groups, for example, imidazole [9], nitrile group [10], pyridyl moiety [11], pyrazolyl [12] and so on [13,14], have been investigated as phosphine-free ligands.

Our research group has also had a long-standing interest in Pd-catalyzed cross-coupling reactions utilizing functionalized-ionic liquids as phosphine-free ligands. Recently we disclosed a catalyst system, comprised of diol-functionalized ILs, 2,2-bis((1-methylimidazolium)methyl) propane-1,3-diol hexafluorophosphate and 1-(2, 3-dihydroxypropyl)-3-methylimidazolium hexaflu-orophosphate, which showed excellent reactivity for Heck reaction of aryl iodides/bromide and acrylates owing to available multi-coordinating sites in these ligands [1518]. In light of these advances, we envisioned that if the use of diol-functionalized ILs could allow Suzuki reaction of aryl iodides/bromides to reach the same efficiencies as Heck reaction. Therefore, in considering further study, we intend to extend the scope of diol-functionalized ILs to explore the reactivity of the Pd-catalysed Suzuki reactions of aryl boronic acids with aryl iodides/bromides/chlorides. In this context, we are interested in applying water-soluble, diol-functionalized ILs 
with different cations as phosphine-free ligands (Scheme 1) in an effort to achieve similar levels of activity that have been achieved in phosphine-containing ligands. It is also noting that the potential of water as a medium for the synthesis has been discussed because of the economy and safety of using water as a solvent.

\section{Results and Discussion}

We initially focused on the Pd-catalyzed coupling reaction of phenyl boronic acid with phenyl iodide in the presence of diol-functionalized IL, 1. The previous studies [19] observed that the choice of solvent was very important for the reaction. Water represents one of the most economically and environmentally viable options. However, catalysts gave low activities when the reaction was carried out in neat water due to the low solubility of phenyl iodide in water. Therefore, $1: 1 \mathrm{CH}_{3} \mathrm{CN} / \mathrm{H}_{2} \mathrm{O}$ was chosen as the solvent in the reactions. In all the reactions, room temperature was adopted with $\mathrm{K}_{2} \mathrm{CO}_{3}$ as a base in the presence of $2.0 \mathrm{~mol} \% \mathrm{PdCl}_{2}$ as well as $4.0 \mathrm{~mol} \%$ diol-functionalized IL ligands.

At the outset of our studies, we found that ligand 1, which was highly efficient for Heck reaction, gave only moderate yield of $78 \%$ for Suzuki reaction with Pd precipitation (Table 1, Entry 1). With careful control of the conditions, it was discovered that method of operating the reaction is very important for the reaction, as low yield was obtained when all substrates was added in $\mathrm{CH}_{3} \mathrm{CN} / \mathrm{H}_{2} \mathrm{O}$. Notably, a significant increase in yield of $96 \%$ occurred when the mixture of phenyl iodide and phenyl boronic acid in $\mathrm{CH}_{3} \mathrm{CN}$ was added into the aqueous $\mathrm{PdCl}_{2}-\mathbf{1}$, and finally $\mathrm{K}_{2} \mathrm{CO}_{3}$ was added (Table 1, Entry 2). Then we examined the efficiency of using $\mathrm{PdCl}_{2}$ in combination with ligands 2 - 9 under the same conditions. Table 1 demonstrates that pyridinium ionic liquid ligands, $\mathbf{7}$ and $\mathbf{8}$, gave only moderate yields for C-C cross-coupling (Table 1, Entries 8 and 9). Similarly, 6 with 1,2-dimethylimidazolium cation and $\mathbf{9}$ comprising of piperidinium also give disappointing results (Table 1, Entries 7,10$)$. On the other hand, other compounds bearing imidazolium cations such as $\mathbf{2}-\mathbf{5}$ are active for this cross-coupling reaction (Table 1, Entries 3-6). Moreover, 2,2-bis((1-hexylimidazolium)methyl) propane-1,3diol hexafluorophosphate $\mathbf{4}$ easily appears to be the most efficient of the ligand tried (Table 1, Entry 5), giving the coupling product in $98 \%$ isolated yields at $30^{\circ} \mathrm{C}$ within $30 \mathrm{~min}$.

In next set of experiments, besides $\mathrm{K}_{2} \mathrm{CO}_{3}$, we examined the influence of altering the bases such as $\mathrm{Na}_{2} \mathrm{CO}_{3}$, $\mathrm{NaHCO}_{3}, \mathrm{NMP}$, pyridine, $\mathrm{Et}_{3} \mathrm{~N}$, and $\left(\mathrm{CH}_{3}\right)_{3} \mathrm{CNH}_{2}$ in the reactions (Table 1, Entries 11-16). This confirms that $\mathrm{K}_{2} \mathrm{CO}_{3}$ was the best of the base tried for both yield and selectivity. The optimum loading of Pd catalyst for the reaction was found to be $2.0 \mathrm{~mol} \%$ along with $4.0 \mathrm{~mol} \%$
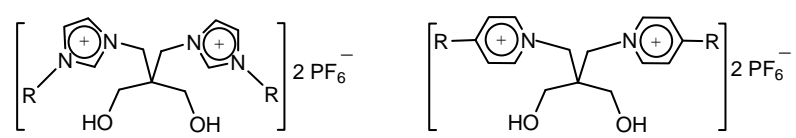

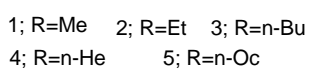

$7 ; \mathrm{R}=\mathrm{H}$

8; $\mathrm{R}=\mathrm{CH}_{3}$
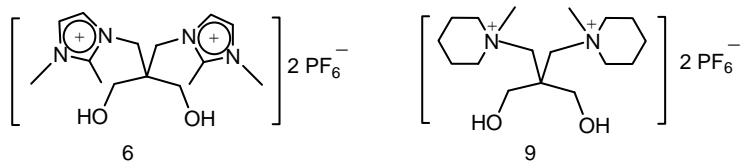

Scheme 1. Ionic liquid-supported diols.

Table 1. The Suzuki reaction of phenyl boronic acid with phenyl iodide ${ }^{a}$.

\begin{tabular}{|c|c|c|c|c|}
\hline Entry & Ligand & Base & Time (h) & Yield $(\%)^{b}$ \\
\hline $1^{c}$ & 1 & $\mathrm{~K}_{2} \mathrm{CO}_{3}$ & 4.0 & 78 \\
\hline $2^{d}$ & 1 & $\mathrm{~K}_{2} \mathrm{CO}_{3}$ & 1.5 & 96 \\
\hline 3 & 2 & $\mathrm{~K}_{2} \mathrm{CO}_{3}$ & 1.5 & 95 \\
\hline 4 & 3 & $\mathrm{~K}_{2} \mathrm{CO}_{3}$ & 1.0 & 96 \\
\hline 5 & 4 & $\mathrm{~K}_{2} \mathrm{CO}_{3}$ & 0.5 & 98 \\
\hline 6 & 5 & $\mathrm{~K}_{2} \mathrm{CO}_{3}$ & 0.75 & 96 \\
\hline 7 & 6 & $\mathrm{~K}_{2} \mathrm{CO}_{3}$ & 1.5 & 74 \\
\hline 8 & 7 & $\mathrm{~K}_{2} \mathrm{CO}_{3}$ & 2.0 & 83 \\
\hline 9 & 8 & $\mathrm{~K}_{2} \mathrm{CO}_{3}$ & 1.8 & 85 \\
\hline 10 & 9 & $\mathrm{~K}_{2} \mathrm{CO}_{3}$ & 6.0 & 68 \\
\hline 11 & 4 & Pyridine & 5.0 & 10 \\
\hline 12 & 4 & $\mathrm{Et}_{3} \mathrm{~N}$ & 1.5 & 66 \\
\hline 13 & 4 & $\left(\mathrm{CH}_{3}\right)_{3} \mathrm{CNH}_{2}$ & 1.5 & 40 \\
\hline 14 & 4 & $\mathrm{Na}_{2} \mathrm{CO}_{3}$ & 0.5 & 90 \\
\hline 15 & 4 & $\mathrm{NaHCO}_{3}$ & 1.0 & 91 \\
\hline 16 & 4 & NMP & 2.0 & 60 \\
\hline $17^{e}$ & 4 & $\mathrm{~K}_{2} \mathrm{CO}_{3}$ & 3.0 & 85 \\
\hline
\end{tabular}

${ }^{a}$ The molar ratios of phenyl iodide/phenyl boronic acid/ $\mathrm{K}_{2} \mathrm{CO}_{3} /$ are $1: 1.2: 2$, the molar ratio of ligand to $\mathrm{PdCl}_{2}$ is $2: 1$, temperature $30^{\circ} \mathrm{C}, \mathrm{CH}_{3} \mathrm{CN} / \mathrm{H}_{2} \mathrm{O}$ (v/v) 2.0/2.0 mL. ${ }^{b}$ Isolated Yields. ${ }^{c} \mathrm{Pd}$ precipitation are found. ${ }^{d}$ ligand and $\mathrm{PdCl}_{2}$ are added to $2.0 \mathrm{~mL} \mathrm{H}_{2} \mathrm{O}$, phenyl iodide and phenyl boronic acid are added to $2.0 \mathrm{~mL} \mathrm{CH}_{3} \mathrm{CN}$. ${ }^{e} \mathrm{PdCl}_{2} 1.5 \mathrm{~mol} \%$.

of ligand (Table 1, Entry 5). However, a significant decrease in the product yield of ( $98 \%$ to $85 \%)$ and increase reaction time $(0.5 \mathrm{~h}$ to $3.0 \mathrm{~h})$ was observed in the reaction when the catalyst loading was decreased from $2.0 \mathrm{~mol} \%$ to $1.5 \mathrm{~mol} \%$, (Table 1, Entry 17).

With a set of optimized conditions in hand, we explored the breadth of application of this new method to a broad range of targets, including aryl boronic acids and aryl iodides/bromides/chlorides substituted by electronwithdrawing and electron-donating groups (Table 2). The $\mathrm{PdCl}_{2}-\mathbf{4}$ system was found to effectively arylate aryl boronic acids with electron-rich and electron-poor aryl 
Table 2. Suzuki reactions of haloarenes with aryl boronic acids $^{a}$.

\begin{tabular}{cccccc} 
& & & & \\
\hline
\end{tabular}

${ }^{a} \mathrm{PdCl}_{2} 2.0 \mathrm{~mol} \%$, IL-supported diol $44.0 \mathrm{~mol} \%$, haloarene $1.0 \mathrm{mmol}$, aryl boronic acid $1.2 \mathrm{mmol}, \mathrm{K}_{2} \mathrm{CO}_{3} 2 \mathrm{mmol}, \mathrm{CH}_{3} \mathrm{CN} / \mathrm{H}_{2} \mathrm{O}(\mathrm{v} / \mathrm{v}) 2.0 / 2.0 \mathrm{~mL}$, temperature $30^{\circ} \mathrm{C} .{ }^{b}$ Isolated yield. ${ }^{c}$ Neat water.

iodides/bromides and gave the desired coupled products in excellent/good/moderate yields in the presence of optimized conditions. However, an attempt to couple $o$ methyl or $o$-trifluoromethyl iodobenzene with phenyl $/ p$ methyl phenyl boronic acid gave a lower yield, probably owing to steric hindrance (Table 2, Entries 4, 5, 10, and 11). Introduction of an electron-releasing methoxy group on aryl boronic acids resulted in moderate yields of the products (Table 2, Entries 7, 8), which is not according with the previous report [19]. Unfortunately, however, a lower yield was obtained with aryl chlorides (Table 2, Entries 15 and 16) probably due to poorer activity of chlorides.

It is all known that using water as a solvent is attractive because of the economy and safety. To further expand substrate scope of this methodology, neat water may be used as the solvent for the Suzuki coupling reaction in the presence of the $\mathrm{PdCl}_{2}-4$ system (Table 2, Entries 17 - 20). The hydrophilic substrates 4-nitrobromobenzene as a substrate was investigated because the former study has shown the importance of water solubility to the conversion. It was pleased that good yields of coupled products $(78 \%-99 \%)$ were obtained in neat water. Notably, reactions appeared to be more sensitive to substituents on aryl boronic acid, as both electron-withdrawing and electron-donating groups gave lower yields in this system.

It is highly desirable that the catalysts can be recovered and reused from the perspective of green chemistry. In case of the reaction with $\mathrm{PdCl}_{2}-4$ we observed that the product had differential solubility from the catalyst-IL in $\mathrm{Et}_{2} \mathrm{O}$. This enables us to extract the product by extraction of the reaction mixture with a minimal amount of $\mathrm{Et}_{2} \mathrm{O}$ whereupon the catalyst-IL was retained in the reaction flask and could be reused. The catalyst $\mathrm{PdCl}_{2}-4$ could be removed from the reaction mixture by extraction and reused at least four times without significant loss of activity and selectivity. After the fourth cycle, it was necessary to separate the aqueous catalyst solution from a large amount of precipitated salts. This extra level of manipulation may have contributed to the significant loss of activity in cycle 5 (Table 3 ).

\section{Conclusion}

In summary, we have disclosed that diol-functionalized IL 4, a phosphine-free ligand, can efficiently promote the Suzuki reaction of aryl boronic acids with aryl halides using $\mathrm{PdCl}_{2}$ as a catalyst under significantly milder conditions. It provides a green ligand for selection of palladium-catalyzed arylation for practical use. The diol-functionalized IL ligands allow coupling reactions of both activated and deactivated aryl iodides/bromides under mild conditions and is tolerant of some degree of steric bulk on the aryl iodides/bromide. Hydrophobic reaction products from the Suzuki reactions can be easily isolated by using ethyl ether. Furthermore, the use of water in combination with renewable catalyst represents an environmentally sustainable approach to the coupling of hydrophilic aryl bromides.

\section{Experimental}

\subsection{General Procedure for Synthesis of Ionic Liquid Ligands}

A mixture of 2,2-bis-(bromomethyl)-propane-1,3-diol (1 mmol) and 1-alkylimidazole/1-alkylpyridine/1,2-dime-

Table 3. Stability study for $\mathrm{PdCl}_{2}-4$ catalyst ${ }^{a}$.

\begin{tabular}{cccccc}
\hline Run & 1 & 2 & 3 & 4 & 5 \\
\hline Yield (\%) & 98 & 95 & 92 & 93 & 85 \\
Time (h) & 2 & 2 & 2 & 3 & 3 \\
\hline
\end{tabular}

${ }^{a} \mathrm{PdCl}_{2} 2.0 \mathrm{~mol} \%$, ligand $44.0 \mathrm{~mol} \%$, 4-nitrobromobenzene $1.0 \mathrm{mmol}$, phenyl boronic acid $1.2 \mathrm{mmol}, \mathrm{K}_{2} \mathrm{CO}_{3} 2 \mathrm{mmol}$ (additionally added per pass), $\mathrm{H}_{2} \mathrm{O}(\mathrm{v} / \mathrm{v}) 4.0 \mathrm{~mL}$ (additionally added per pass), tmperature $30^{\circ} \mathrm{C}$. ${ }^{b}$ Isolated yield. Reaction time was indicated in the parenthesis. 
thylimidazole/1-methyl piperidine $(3 \mathrm{mmol})$ was stirred vigorously at $150^{\circ} \mathrm{C}$ for $8 \mathrm{~h}$. After cooling to room temperature, the crude product was washed with acetone. The resulting solid collected by filtration was treated with water $(5 \mathrm{~mL})$ as well as $\mathrm{KPF}_{6}(2 \mathrm{mmol})$ and the reaction mixture was stirred at room temperature for $1 \mathrm{~h}$. After filtration, the white solid was washed with ethanol and dried in vacuo to give the desired product.

\subsection{The NMR and FT-IR Data for the Products}

2,2-bis((1-methylimidazolium)methyl) propane-1,3-diol hexafluorophosphate (1). White solid (0.47 g, 84\%); FT-IR (KBr) v: 3604, 3165, 3122, 2977, 2913, 1588, $1577,1448,1425,1301,1173,1014,846 \mathrm{~cm}^{-1}$. ${ }^{1} \mathrm{H}$ NMR $\left(\mathrm{DMSO}-d_{6}, 500 \mathrm{MHz}\right) \delta: 3.10\left(\mathrm{~d}, J=4 \mathrm{~Hz}, 4 \mathrm{H}, \mathrm{OH}-\mathrm{CH}_{2}\right)$, $3.90\left(\mathrm{~s}, 6 \mathrm{H}, \mathrm{CH}_{3}\right), 4.25\left(\mathrm{~s}, 4 \mathrm{H}, \mathrm{N}-\mathrm{CH}_{2}\right), 5.25\left(\mathrm{t}, J_{1}=5 \mathrm{~Hz}\right.$, $\left.J_{2}=4 \mathrm{~Hz}, 2 \mathrm{H}, \mathrm{OH}\right), 7.70(\mathrm{~s}, 2 \mathrm{H}, \mathrm{NCH}), 7.80(\mathrm{~s}, 2 \mathrm{H}$, $\mathrm{NCH}), 9.15$ (s, 2H, N $(H) \mathrm{CN})$.

2,2-bis((1-ethylimidazolium)methyl) propane-1,3-diol hexafluorophosphate (2). White solid (0.42 g, 72\%); FT-IR (KBr) v: 3620, 3590, 3180, 1560, 1460, 1350, $1160,1060,839 \mathrm{~cm}^{-1}$. ${ }^{1} \mathrm{H}$ NMR (DMSO- $\left.d_{6}, 500 \mathrm{MHz}\right) \delta$ : $1.42\left(\mathrm{t}, 6 \mathrm{H}, \mathrm{J}=5 \mathrm{~Hz}, \mathrm{CH}_{2}-\mathrm{CH}_{3}\right), 3.11(\mathrm{~d}, 4 \mathrm{H}, \mathrm{J}=5 \mathrm{~Hz}$, $\left.\mathrm{CH}_{2}-\mathrm{OH}\right), 4.20$ (q, 4H, N-CH $-\mathrm{CH}_{3}$ ), 4.22 (s, 4H, N-CH $)$, $5.32(\mathrm{t}, 2 \mathrm{H}, \mathrm{J}=5 \mathrm{~Hz}, \mathrm{OH}), 7.62(\mathrm{~s}, 2 \mathrm{H}, \mathrm{NCH}), 7.84(\mathrm{~s}$, 2H, NCH), 9.03 (s, 2H, N $(H) \mathrm{CN})$.

2,2-bis((1-butylimidazolium)methyl) propane-1,3-diol hexafluorophosphate (3). White solid (0.46 g, 72\%); FT-IR (KBr) v: 3600, 3160, 2970, 2930, 1570, 1450, $1170,1020,845 \mathrm{~cm}^{-1} .{ }^{1} \mathrm{H}$ NMR (DMSO- $\left.d_{6}, 500 \mathrm{MHz}\right) \delta$ : $0.90\left(\mathrm{t}, 6 \mathrm{H}, \mathrm{J}=5 \mathrm{~Hz},\left(\mathrm{CH}_{2}\right)_{3}-\mathrm{CH}_{3}\right), 1.25(\mathrm{~m}, 4 \mathrm{H}$, $\left.\left(\mathrm{CH}_{2}\right)_{2} \mathrm{CH}_{2}-\mathrm{CH}_{3}\right), 1.77$ (m, 4H, $\left.\mathrm{CH}_{2}-\mathrm{CH}_{2}-\mathrm{CH}_{2}-\mathrm{CH}_{3}\right), 3.11$ $\left(\mathrm{d}, 4 \mathrm{H}, \mathrm{J}=5 \mathrm{~Hz}, \mathrm{CH}_{2}-\mathrm{OH}\right), 4.18(\mathrm{t}, 4 \mathrm{H}, \mathrm{J}=5 \mathrm{~Hz}$, $\left.\mathrm{N}-\mathrm{CH}_{2}-\left(\mathrm{CH}_{2}\right)_{2} \mathrm{CH}_{3}\right), 4.24\left(\mathrm{~s}, 4 \mathrm{H}, \mathrm{N}-\mathrm{CH}_{2}\right), 5.31$ (t, 2H, J $=5 \mathrm{~Hz}, \mathrm{OH}), 7.64(\mathrm{~s}, 2 \mathrm{H}, \mathrm{NCH}), 7.84(\mathrm{~s}, 2 \mathrm{H}, \mathrm{NCH}), 9.05$ (s, 2H, N $(H) \mathrm{CN})$.

2,2-bis((1-hexylimidazolium)methyl) propane-1,3-diol hexafluorophosphate (4). White solid (0.45 g, 65\%); FT-IR (KBr) v: 3610, 3180, 3060, 2960, 2930, 2860, 1570, 1460, 1170, 1010, $839 \mathrm{~cm}^{-1}$. ${ }^{1} \mathrm{H}$ NMR (DMSO- $d_{6}$, $500 \mathrm{MHz}) \delta: 1.55\left(\mathrm{t}, 6 \mathrm{H}, \mathrm{J}=5 \mathrm{~Hz},\left(\mathrm{CH}_{2}\right)_{5}-\mathrm{CH}_{3}\right), 1.96(\mathrm{~m}$, $\left.12 \mathrm{H},\left(\mathrm{CH}_{2}\right)_{2}-\left(\mathrm{CH}_{2}\right)_{3}-\mathrm{CH}_{3}\right), 3.80(\mathrm{~d}, 4 \mathrm{H}, \mathrm{J}=2.5 \mathrm{~Hz}$, $\left.\mathrm{CH}_{2}-\mathrm{OH}\right), 4.02\left(\mathrm{~m}, 4 \mathrm{H}, \mathrm{CH}_{2}-\mathrm{CH}_{2}-\left(\mathrm{CH}_{2}\right)_{3}-\mathrm{CH}_{3}\right), 4.88$ (t, $\left.4 \mathrm{H}, \mathrm{J}=5 \mathrm{~Hz}, \mathrm{~N}-\mathrm{CH}_{2}-\left(\mathrm{CH}_{2}\right)_{4}-\mathrm{CH}_{3}\right), 4.96\left(\mathrm{~s}, 4 \mathrm{H}, \mathrm{N}-\mathrm{CH}_{2}\right)$, $6.02(\mathrm{t}, 2 \mathrm{H}, \mathrm{J}=5 \mathrm{~Hz}, \mathrm{OH}), 8.36(\mathrm{~s}, 2 \mathrm{H}, \mathrm{NCH}), 8.54(\mathrm{~s}$, $2 \mathrm{H}, \mathrm{NCH}), 9.82(\mathrm{~s}, 2 \mathrm{H}, \mathrm{N}(H) \mathrm{CN})$.

2,2-bis((1-octylimidazolium)methyl) propane-1,3-diol hexafluorophosphate (5). White solid (0.58 g, 77\%); FT-IR (KBr) v: 3610, 3170, 2920, 2850, 1570, 1460, $1180,1010,837 \mathrm{~cm}^{-1} .{ }^{1} \mathrm{H}$ NMR (DMSO- $\left.d_{6}, 500 \mathrm{MHz}\right) \delta$ : (t, 6H, J = $\left.5 \mathrm{~Hz},\left(\mathrm{CH}_{2}\right)_{7}-\mathrm{CH}_{3}\right), 1.24\left(\mathrm{~m}, 20 \mathrm{H},\left(\mathrm{CH}_{2}\right)_{2}-\right.$ $\left.\left(\mathrm{CH}_{2}\right)_{5}-\mathrm{CH}_{3}\right), 1.79\left(\mathrm{~m}, 4 \mathrm{H}, \mathrm{CH}_{2}-\mathrm{CH}_{2}-\left(\mathrm{CH}_{2}\right)_{5}-\mathrm{CH}_{3}\right), 3.09$ (d, $\left.4 \mathrm{H}, \mathrm{J}=5 \mathrm{~Hz}, \mathrm{CH}_{2}-\mathrm{OH}\right), 4.17(\mathrm{t}, 4 \mathrm{H}, \mathrm{J}=5 \mathrm{~Hz}$,
$\left.\mathrm{N}-\mathrm{CH}_{2}-\left(\mathrm{CH}_{2}\right)_{6}-\mathrm{CH}_{3}\right), 4.24\left(\mathrm{~s}, 4 \mathrm{H}, \mathrm{N}-\mathrm{CH}_{2}\right), 5.31(\mathrm{t}, 2 \mathrm{H}, \mathrm{J}$ $=5 \mathrm{~Hz}, \mathrm{OH}), 7.63(\mathrm{~s}, 2 \mathrm{H}, \mathrm{NCH}), 7.84(\mathrm{~s}, 2 \mathrm{H}, \mathrm{NCH}), 9.04$ (s, 2H, N $(H) \mathrm{CN})$.

2,2-bis((1,2-dimethylimidazolium)methyl) propane-1, 3-diol hexafluorophosphate (6). White solid (0.40 g, $68 \%$ ); FT-IR (KBr) v: 3605, 3160, 2980, 1590, 1570, $1450,1430,1300,1171,1015,840 \mathrm{~cm}^{-1} .{ }^{1} \mathrm{H}$ NMR $\left(\mathrm{DMSO}-d_{6}, 500 \mathrm{MHz}\right) \delta: 2.64\left(\mathrm{~s}, 6 \mathrm{H}, \mathrm{CH}_{3}\right), 3.11(\mathrm{~d}, 4 \mathrm{H}$, $\left.\mathrm{J}=1.5 \mathrm{~Hz}, \mathrm{OH}-\mathrm{CH}_{2}\right), 3.76\left(\mathrm{~s}, 6 \mathrm{H}, \mathrm{N}-\mathrm{CH}_{3}\right), 4.19(\mathrm{~s}, 4 \mathrm{H}$, $\left.\mathrm{N}-\mathrm{CH}_{2}\right), 5.41(\mathrm{~s}, 2 \mathrm{H}, \mathrm{OH}), 7.50(\mathrm{~s}, 2 \mathrm{H}, \mathrm{NCH}), 7.68(\mathrm{~s}$, $2 \mathrm{H}, \mathrm{NCH})$.

2,2-bis((1-pyridinium)methyl) propane-1,3-diol hexafluorophosphate (7). White solid (0.39 g, 71\%); FT-IR (KBr) v: 3608, 3060, 2880, 1592, 1575, 1455, 1432, $1301,1170,1015,837 \mathrm{~cm}^{-1} .{ }^{1} \mathrm{H}$ NMR (DMSO- $d_{6}, 500$ $\mathrm{MHz}) \delta: 3.16\left(\mathrm{~s}, 4 \mathrm{H}, \mathrm{OH}-\mathrm{CH}_{2}\right), 4.78\left(\mathrm{~s}, 4 \mathrm{H}, \mathrm{N}-\mathrm{CH}_{2}\right)$, $5.58(\mathrm{~s}, 2 \mathrm{H}, \mathrm{OH}), 8.19(\mathrm{~m}, 4 \mathrm{H}, \mathrm{m}-\mathrm{CH}), 8.67(\mathrm{~m}, 2 \mathrm{H}$, p-CH), 8.91 (d, 4H, o-CH).

2,2-bis((4-methylpyridinium)methyl) propane-1,3-diol hexafluorophosphate (8). White solid (0.40 g, 69\%); FT-IR (KBr) v: 3601, 3040, 2981, 2855, 1580, 1564, $1450,1425,1310,1168,1019,843 \mathrm{~cm}^{-1}$. ${ }^{1} \mathrm{H}$ NMR (DMSO-d $6,500 \mathrm{MHz}) \delta: 2.64\left(\mathrm{~s}, 6 \mathrm{H}, \mathrm{CH}_{3}\right), 3.13(\mathrm{~s}, 4 \mathrm{H}$, $\left.\mathrm{OH}-\mathrm{CH}_{2}\right), 4.69$ (s, 4H, N-CH $\left.\mathrm{C}_{2}\right), 5.57(\mathrm{~s}, 2 \mathrm{H}, \mathrm{OH}), 8.03$ (m, 8H, Ar- $H)$.

2,2-bis((1-methylpiperidinium)methyl) propane-1,3diol hexafluorophosphate (9). White solid (0.18 g, 31\%); FT-IR (KBr) v: 3605, 2987, 2886, 1500, 1445, 1423, 1306 1164, 1010, $845 \mathrm{~cm}^{-1}$. ${ }^{1} \mathrm{H}$ NMR (DMSO-d 6,500 $\mathrm{MHz}) \delta: 3.02\left(\mathrm{~s}, 6 \mathrm{H}, \mathrm{CH}_{3}\right), 3.40\left(\mathrm{~m}, 12 \mathrm{H}, \mathrm{CH}_{2}-\mathrm{CH}_{2}-\mathrm{CH}_{2}\right)$ 3.79 (s, 4H, OH-CH$), 3.90$ (d, 4H, N-CH $), 4.23(\mathrm{~m}, 4 \mathrm{H}$, $\left.\mathrm{N}-\mathrm{CH}_{2}\right), 4.55\left(\mathrm{~m}, 4 \mathrm{H}, \mathrm{N}-\mathrm{CH}_{2}\right), 5.63(\mathrm{~d}, 2 \mathrm{H}, \mathrm{J}=4 \mathrm{~Hz}$, $\mathrm{OH})$.

\subsection{General Procedure for Suzuki Reaction in $\mathrm{H}_{2} \mathrm{O}$ and Recovery of Catalyst}

In a typical experiment, a mixture of ligand (4.0 mol\%) with $\mathrm{PdCl}_{2}(2.0 \mathrm{~mol} \%)$ in water $(4.0 \mathrm{~mL})$ was added 4 nitrobromobenzene $(0.19 \mathrm{~g}, 1 \mathrm{mmol})$ and phenyl boronic acid $(1.2 \mathrm{mmol})$, and then $\mathrm{K}_{2} \mathrm{CO}_{3}(0.28 \mathrm{~g}, 2 \mathrm{mmol})$ was added. The mixture was reacted at $30^{\circ} \mathrm{C}$. On completion monitored by TLC and GC, the reaction mixture was extracted with ethyl ether $(10 \mathrm{~mL} \times 3)$. The combined organic extracts were washed with $10 \% \mathrm{NaOH}(10 \mathrm{~mL} \times$ 3 ), dried with $\mathrm{Na}_{2} \mathrm{SO}_{4}$, filtered and concentrated under vacuum to give the desired product. MS (GC/MS) $m / z$ : $154\left(\mathrm{M}^{+}, 100 \%\right), 77$ (10\%), 51 (8\%). ${ }^{1} \mathrm{H}$ NMR (500 MHz, DMSO- $\left.d_{6}, \mathrm{ppm}\right): \delta_{\mathrm{H}} 7.40-7.60(\mathrm{~m}, 10 \mathrm{H}, \mathrm{ArH})$.

The remaining liquid phase composed of $\mathrm{PdCl}_{2}$, ligand and the formed salt of $\mathrm{KCO}_{3}$ was used directly without further treatment for the next run through treated with 4nitrobromobenzene $(0.19 \mathrm{~g}, 1 \mathrm{mmol})$, phenyl boronic acid (0.18 g, $1.5 \mathrm{mmol}), \mathrm{K}_{2} \mathrm{CO}_{3}(0.28 \mathrm{~g}, 2 \mathrm{mmol})$ again. 


\section{Acknowledgements}

We acknowledge the Natural Science Foundation of China (Grant 20676033), China Postdoctoral Science Foundation (Grant 20070410169) and Shanghai Leading Academic Discipline Project (Project Number: B507) for financial support.

\section{REFERENCES}

[1] N. Miyaura and A. Suzuki, "Palladium-Catalyzed CrossCoupling Reactions of Organoboron Compounds," Chemical Reviews, Vol. 95, No. 7, 1995, pp. 2457-2483. http://dx.doi.org/10.1021/cr00039a007

[2] A. Suzuki, "Recent Advances in the Cross-Coupling Reactions of Organoboron Derivatives with Organic Electrophiles, 1995-1998," Journal of Organometallic Chemistry, Vol. 576, No. 1-2, 1999, pp. 147-168. http://dx.doi.org/10.1016/S0022-328X(98)01055-9

[3] R. B. Bedford, C. S. J. Cazin and D. Holder, "The Development of Palladium Catalysts for $\mathrm{C}-\mathrm{C}$ and $\mathrm{C}-\mathrm{Het}-$ eroatom Bond Forming Reactions of Aryl Chloride Substrates," Coordination Chemistry Reviews, Vol. 248, No. 21-24, 2004, pp. 2283-2321.

http://dx.doi.org/10.1016/i.ccr.2004.06.012

[4] C. Amatore and A. Jutand, "Anionic $\operatorname{Pd}(0)$ and $\operatorname{Pd}(\mathrm{II})$ Intermediates in Palladium-Catalyzed Heck and CrossCoupling Reactions," Accounts of Chemical Research, Vol. 33, No. 5, 2000, pp. 314-321. http://dx.doi.org/10.1021/ar980063a

[5] V. Calo, A. Nacci, A. Monopoli, A. Fornaro, L. Sabbatini, N. Cioffi and N. Ditaranto, "Heck Reaction Catalyzed by Nanosized Palladium on Chitosan in Ionic Liquids," Organometallics, Vol. 23, No. 22, 2004, pp. 5154-5158.

[6] V. Calo, A. Nacci, A. Monopoli, E. Ieva and N. Cioffi, "Copper Bronze Catalyzed Heck Reaction in Ionic Liquids," Organic Letters, Vol. 7, No. 4, 2005, pp. 617-620. http://dx.doi.org/10.1021/o1047593t

[7] D. Zhao, Z. Fei, R. Scopelliti and P. J. Dyson, "Synthesis and Characterization of Ionic Liquids Incorporating the Nitrile Functionality," Inorganic Chemistry, Vol. 43, No. 6, 2004, pp. 2197-2205. http://dx.doi.org/10.1021/ic034801p

[8] N. Audic, H. Clavéier, M. Mauduit and J.-C. Guillemin, "An Ionic Liquid-Supported Ruthenium Carbene Complex: A Robust and Recyclable Catalyst for Ring-Closing Olefin Metathesis in Ionic Liquids," Journal of the American Chemical Society, Vol. 125, No. 31, 2003, pp. 92489249. http://dx.doi.org/10.1021/ja021484x

[9] J. C. Xiao, B. Twamley and J. M. Shreeve, "An Ionic Liquid-Coordinated Palladium Complex: A Highly Efficient and Recyclable Catalyst for the Heck Reaction," Organic Letters, Vol. 6, No. 21, 2004, pp. 3845-3847. http://dx.doi.org/10.1021/ol048327i

[10] D. Zhao, Z. Fei, T. J. Geldbach, R. Scopelliti and P. J.
Dyson, "Nitrile-Functionalized Pyridinium Ionic Liquids: Synthesis, Characterization, and Their Application in Carbon-Carbon Coupling Reactions," Journal of the American Chemical Society, Vol. 126, No. 48, 2004, pp. 15876-15882. http://dx.doi.org/10.1021/ja0463482

[11] R. Wang, J.-C. Xiao, B. Twamley and J. N. M. Shreeve, "Efficient Heck Reactions Catalyzed by A Highly Recyclable Palladium(II) Complex of a Pyridyl-Functionalized Imidazolium-Based Ionic Liquid," Organic \& Biomolecular Chemistry, Vol. 5, No. 4, 2007, pp. 671-678. http://dx.doi.org/10.1039/b616529j

[12] R. Wang, M. M. Piekarski and J. N. M. Shreeve, "Pyrazolyl-Functionalized 2-Methylimidazolium-Based Ionic Liquids and Their Palladium(II) Complexes as Recyclable Catalysts," Organic \& Biomolecular Chemistry, Vol. 4, No. 10, 2006, pp. 1878-1886.

http://dx.doi.org/10.1039/b604008j

[13] S. Li, Y. J. Lin, H. B. Xie, S. B. Zhang and J. N. Xu, "Brønsted Guanidine Acid-Base Ionic Liquids: Novel Reaction Media for the Palladium-Catalyzed Heck Reaction," Organic Letters, Vol. 8, No. 3, 2006, pp. 391-394. http://dx.doi.org/10.1021/o1052543p

[14] J. C. Xiao and J. M. Shreeve, 'Synthesis of 2,2'-Biimidazolium-Based Ionic Liquids: Use as a New Reaction Medium and Ligand for Palladium-Catalyzed Suzuki CrossCoupling Reactions," The Journal of Organic Chemistry, Vol. 70, No. 8, 2005, pp. 3072-3078. http://dx.doi.org/10.1021/jo0501083

[15] Y.Q. Cai, Y. Lu, Y. Liu and G. H. Gao, "Imidazolium Ionic Liquid-Supported Diol: an Efficient and Recyclable Phosphine-free Ligand for Palladium Catalyzed Heck Reaction," Catalysis Letters, Vol. 119, No. 1-2, 2007, pp. 154-158. http://dx.doi.org/10.1007/s10562-007-9213-7

[16] Y. Q. Cai, Y. Lu, Y. Liu, M. Y. He and Q. X. Wan, "Efficient Heck Reactions Catalyzed by a Palladium/DiolImidazolium Salt in Aerial Atmosphere," Catalysis Communications, Vol. 9, No. 6, 2008, pp. 1209-1213. http://dx.doi.org/10.1016/j.catcom.2007.11.004

[17] Y. Q. Cai and Y. Lu, "Efficient Palladium-Catalyzed Heck Reactions Mediated by the Diol-Functionalized Imidazolium Ionic Liquids," Catalysis Communications, Vol. 10, No. 10, 2009, pp. 1390-1393. http://dx.doi.org/10.1016/j.catcom.2009.03.003

[18] Y. Q. Cai, G. H. Song and X. Y. Zhou, "Aqueous-Phase, Palladium-Catalyzed Heck Reaction: The Significant Role of CN-Containing Counter Anion," Chinese Journal of Chemistry, Vol. 30, No. 12, 2012, pp. 2819-2822. http://dx.doi.org/10.1002/cjoc.201200675

[19] R. B. DeVasher, L. R. Moore and K. H. Shaughnessy, "Aqueous-Phase, Palladium-Catalyzed Cross-Coupling of Aryl Bromides under Mild Conditions, Using WaterSoluble, Sterically Demanding Alkylphosphines," The Journal of Organic Chemistry, Vol. 69, No. 23, 2004, pp. 7919-7927. http://dx.doi.org/10.1021/jo048910c 